Review

\title{
Endogenous sex steroid hormones and colorectal cancer risk: a systematic review and meta-analysis
}

\author{
Emmanouil Bouras $^{1}$ (D) $\cdot$ Christopher Papandreou ${ }^{2}$ (D) $\cdot$ Ioanna Tzoulaki $^{1,3}$ (D) Konstantinos K. Tsilidis $^{1,3}$ (D)
}

Received: 31 January 2021 / Accepted: 2 March 2021

(c) The Author(s) 2021 OPEN

\begin{abstract}
Preclinical data suggest that endogenous sex steroid hormones may be implicated in colorectal cancer (CRC) development, however, findings from epidemiological studies are conflicting. The aim of this systematic review and meta-analysis was to investigate the associations between endogenous concentrations of sex hormones and CRC risk. PubMed and Scopus were searched until June 2020 for prospective studies evaluating the association between pre-diagnostic plasma/ serum concentrations of estradiol, testosterone and sex-hormone binding globulin (SHBG) and CRC risk. Summary relative risks (RRs) and 95\% confidence intervals (Cls) were estimated using the inverse-variance weighted random-effects model based on the DerSimonian-Laird estimator. Eight studies were included in the meta-analysis after evaluating 3,859 non-duplicate records. Four of the eight studies had a nested case-control design, one study was a case-cohort and the rest three studies were cohort studies, and they included on average 295 cases (range:48-732) and 2,105 controls. No associations were found for endogenous sex steroid hormones in men or post-menopausal women with CRC risk, with evidence for substantial heterogeneity observed among women. Findings from this meta-analysis do not support presence of associations between pre-diagnostic concentrations of testosterone, estradiol and SHBG with incident CRC risk in men and post-menopausal women.
\end{abstract}

Keywords Estradiol · Testosterone $\cdot$ Sex-hormone binding globulin $\cdot$ Colorectal cancer $\cdot$ Systematic review $\cdot$ Metaanalysis

\section{Introduction}

Colorectal cancer (CRC) is the third most frequent cancer in males and second in females worldwide, with almost one million new incident cases in 2018 [1]. Sex differences in CRC development have been suggested [2, 3] and in support of this notion are the findings from several epidemiological studies [4-8] showing a higher incidence in men, with agestandardised incidence rates of 23.4 per 100,000 compared to 16.2 in females, worldwide [1,9]. Furthermore, a protective role of exogenous hormones, such as oral contraceptives and postmenopausal hormone therapy, is observed for CRC risk [10-13]. However, the role of endogenous concentrations of sex hormones, such as estradiol, testosterone and

Emmanouil Bouras and Christopher Papandreou authors contributed equally and are joint first.

Supplementary Information The online version contains supplementary material available at https://doi.org/10.1007/s12672-02100402-z.

Konstantinos K. Tsilidis, k.tsilidis@imperial.ac.uk | 'Department of Hygiene and Epidemiology, University of loannina Medical School, loannina, Greece. ${ }^{2}$ Institut D'Investigació Sanitària Pere Virgili (IISPV), Reus, Spain. ${ }^{3}$ Department of Epidemiology and Biostatistics, School of Public Health, Imperial College London, St Mary's Campus, London W2 1PG, UK.

Discover Oncology $\quad$ (2021) $12: 8 \quad$ https://doi.org/10.1007/s12672-021-00402-z

Published online: 15 March 2021 
sex-hormone binding globulin (SHBG), in CRC risk is unclear. Preclinical data suggest a potential role of estradiol and testosterone in the aetiology of CRC [14, 15]. Estrogen through its receptors have been shown to activate diverse intracellular pathways, including protein kinase C (PKC), intracellular Ca2+, cytosolic CAMP, nitric oxide and MAPK, that are implicated in cancer [16]. Experimental evidence also suggest that testosterone is implicated in colon cancer cell apoptosis, mediated through the activation of specific membrane-binding sites and the subsequent regulation of the PI3K/Akt pathway, apoptotic proteins of Bcl-2 family, Bad, and the reorganization of actin cytoskeleton through small GTPase signalling, including CDC42, RAC1 and RhoA/B [17]. A significant positive association between endogenous estradiol concentrations and CRC incidence was found among postmenopausal women in the Women's Health Initiative Observational Study (WHI-OS) [18]. However, two case-control studies, one nested within the New York University Women's Health Study (NYUWHS) [19] and another nested within 4 US cohort studies [2] reported no significant association between estradiol concentrations and CRC risk. Contradictory findings also exist in relation to circulating testosterone and CRC risk. Higher concentrations of testosterone have been associated with a decreased risk of CRC in men [2] and increased risk in postmenopausal women [20]. Other prospective studies examining this association showed null findings [21-24]. Similarly, conflicting results emerged on other components of the endogenous sex hormone axis, including SHBG, in two prospective studies (WHI-OS, 4 US studies) reporting no significant findings [2, 19], whereas a significant positive association was reported in the follow-up of the Women's Health Initiative Clinical Trial (WHI-CT) [25].

Summarizing the available evidence on the role of endogenous sex steroid hormones on CRC risk could assist in understanding better the hormonal perturbations associated with CRC development. Therefore, we conducted a systematic review and meta-analysis for the association of circulating endogenous concentrations of estradiol, testosterone and SHBG with CRC risk combining results from prospective epidemiological investigations conducted in men and women.

\section{Methods}

\subsection{Literature search and data extraction}

We searched for eligible published studies in MEDLINE-PubMed and Elsevier's Scopus databases up to 17 June, 2020 using the search algorithm described in Additional file 1: Table S1. All studies obtained from the literature searches were uploaded in the web-based application of rayyan, which was used to manage the study selection process [26]. We considered only prospective epidemiological studies assessing the association between pre-diagnostic concentrations of endogenous sex steroid hormones, namely plasma or serum estradiol, testosterone and SHBG, and risk of developing CRC. We excluded non-human and in-vitro studies, narrative or systematic reviews, case-series or case-reports, crosssectional studies, studies on CRC survival, studies conducted in children, duplicate studies, studies that did not provide enough information for calculating measures of association, and studies in other than the English language. When there were more than one studies from the same cohort, we selected the publication with the longer follow-up [21].

Screening of eligible studies and data extraction were performed independently by two investigators (EB and CP), and data was re-checked for consistency by a third author (KT). We initially removed duplicate publications from the electronic databases, and screened the titles and abstracts for eligibility in a blinded manner using rayyan. After the primary screening, the full texts of eligible studies were retrieved, and the inclusion and exclusion criteria were assessed. The "Newcastle-Ottawa Scale" [27] was used to assess the quality of the included studies. The assessment was based on the following criteria: 1) study selection (maximum 4 points); 2) adequacy of the exposure or outcome for nested case-control and cohort studies, respectively (maximum 3 points); and 3) comparability of study groups (maximum 2 points). The studies were categorized as either high quality or low quality. The maximum score was 9 , and a score of $\geq 6$ indicated high methodological quality.

The data extracted from each eligible study included the following: first authors' name and year of publication, country, study design, duration of follow-up, population characteristics such as age and sex, number of cases and controls, exposure and method of assessment, association estimates per level of exposure and adjustment factors. In case of multivariable adjusted statistical models, we retained the most adjusted model. 


\subsection{Statistical analyses}

Our primary analysis was a dose-response meta-analysis model considering continuous association estimates by sex. In studies, where association estimates per exposure were presented as three or more categories, generalized least-square regression was used to estimate the linear trends and express the association as per unit increase, using the method proposed by Greenland \& Longnecker [28]. Specifically, we used the median concentrations of sex steroid hormones per tertile or quartile to represent the respective doses of the hormones. We used conversion factors (CF) based on the International System of Units (SI) to consider the doses under common units for each exposure (CF for estradiol: 1 pg/ $\mathrm{mL}=3.67 \mathrm{pmol} / \mathrm{L} ; \mathrm{CF}$ for testosterone: $1 \mathrm{ng} / \mathrm{dL}=34.67 \mathrm{pmol} / \mathrm{L}$ ).

The inverse-variance weighted random-effects DerSimonian-Laird meta-analysis [29, 30] was applied to estimate the pooled estimate for each of the associations of interest. Summary relative risks (RRs) and $95 \% \mathrm{Cls}$ were calculated. A twotailed $P<0.05$ was considered statistically significant. The presence of heterogeneity was assessed using Cochran's $Q$ test and the degree of heterogeneity was evaluated using the $I^{2}$ metric. $I^{2}$ values $\geq 50 \%$ indicated substantial heterogeneity [31]. Prediction intervals that provide an estimate of the interval within which a new study's estimate would fall were also estimated as proposed by Higgins [32].

As a secondary analysis, we also meta-analysed the extreme quartiles of the endogenous sex hormone concentrations. All analyses were performed in R v.4.0.2 [33].

\section{Results}

\subsection{Study selection}

The initial search yielded 3,859 non-duplicate records and after further screening, eight studies were deemed eligible for inclusion in the meta-analysis, namely three prospective cohorts [22-24], one case-cohort study [18] and four nested case-control studies [2, 19, 20, 25] (Fig. 1).

\subsection{Study characteristics}

Table 1 shows the main characteristics of the selected studies. Three of the studies were from the USA, two from Australia, and one each from the UK, Denmark and Japan. The number of cases in the single studies ranged from 48 to 732 . In total, the cohort studies included 13,876 participants with 454 cases, the case-cohort study included 438 cases and the nested case-control studies included 1,466 cases and 2,612 controls (Table 1). All of the included studies were of high quality with a mean of 8.5 points in the Newcastle-Ottawa scale (range: 7-9) (Additional file 1: Tables S2, S3).

\subsection{Evidence synthesis}

Summary random- and fixed-effects RRs and $95 \% \mathrm{Cls}$, and heterogeneity statistics by sex are shown in Figs. 2, 3, 4 . Due to the substantial heterogeneity among studies examining the relationship between endogenous sex hormones and CRC in women, we report results derived from the random-effects meta-analyses. No significant associations were observed in the dose-response meta-analyses for estradiol (RR per $10 \mathrm{pg} / \mathrm{ml}=1.05,95 \% \mathrm{Cl}: 0.95-1.16, \mathrm{I}^{2}=0 \%$ in men; RR per $10 \mathrm{pg} / \mathrm{ml}=1.06,95 \% \mathrm{Cl}: 0.88-1.28, \mathrm{I}^{2}=53 \%$ in post-menopausal women) and testosterone (RR per $100 \mathrm{ng} / \mathrm{dL}=0.97$, $95 \% \mathrm{Cl}: 0.92-1.03, \mathrm{I}^{2}=31 \%$ in men; RR per $10 \mathrm{ng} / \mathrm{dL}=1.06 ; 95 \% \mathrm{Cl}: 0.94-1.20, \mathrm{I}^{2}=62 \%$ in post-menopausal women). SHBG was also not significantly associated with CRC risk (RR per $10 \mathrm{nmol} / \mathrm{L}=0.94,95 \% \mathrm{Cl}: 0.85-1.05, \mathrm{I}^{2}=43 \%$ in men; RR per $10 \mathrm{nmol} / \mathrm{L}=1.02,95 \% \mathrm{Cl}: 0.96-1.09, \mathrm{I}^{2}=76 \%$ in post-menopausal women).

In the comparisons of the top vs. bottom quartile of sex hormones concentrations, the meta-analyses showed a significant positive association between testosterone and CRC in post-menopausal women but only two studies were included ( $\mathrm{RR}=1.7,95 \% \mathrm{Cl}: 1.11-2.6 ; \mathrm{I}^{2}=0 \%$ ), while no significant associations were observed for estradiol or SHBG (Additional file 1: Figure S1). 


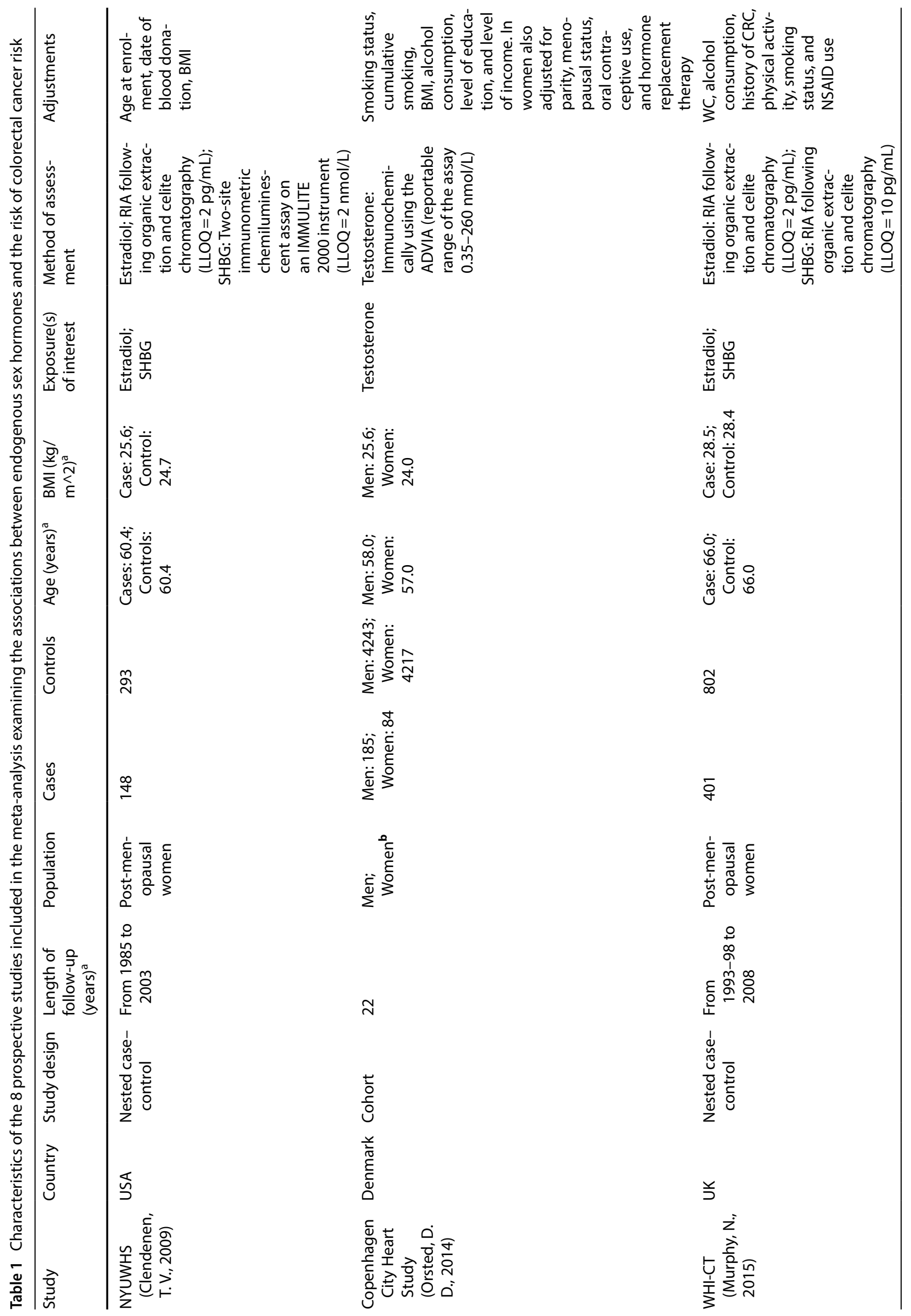




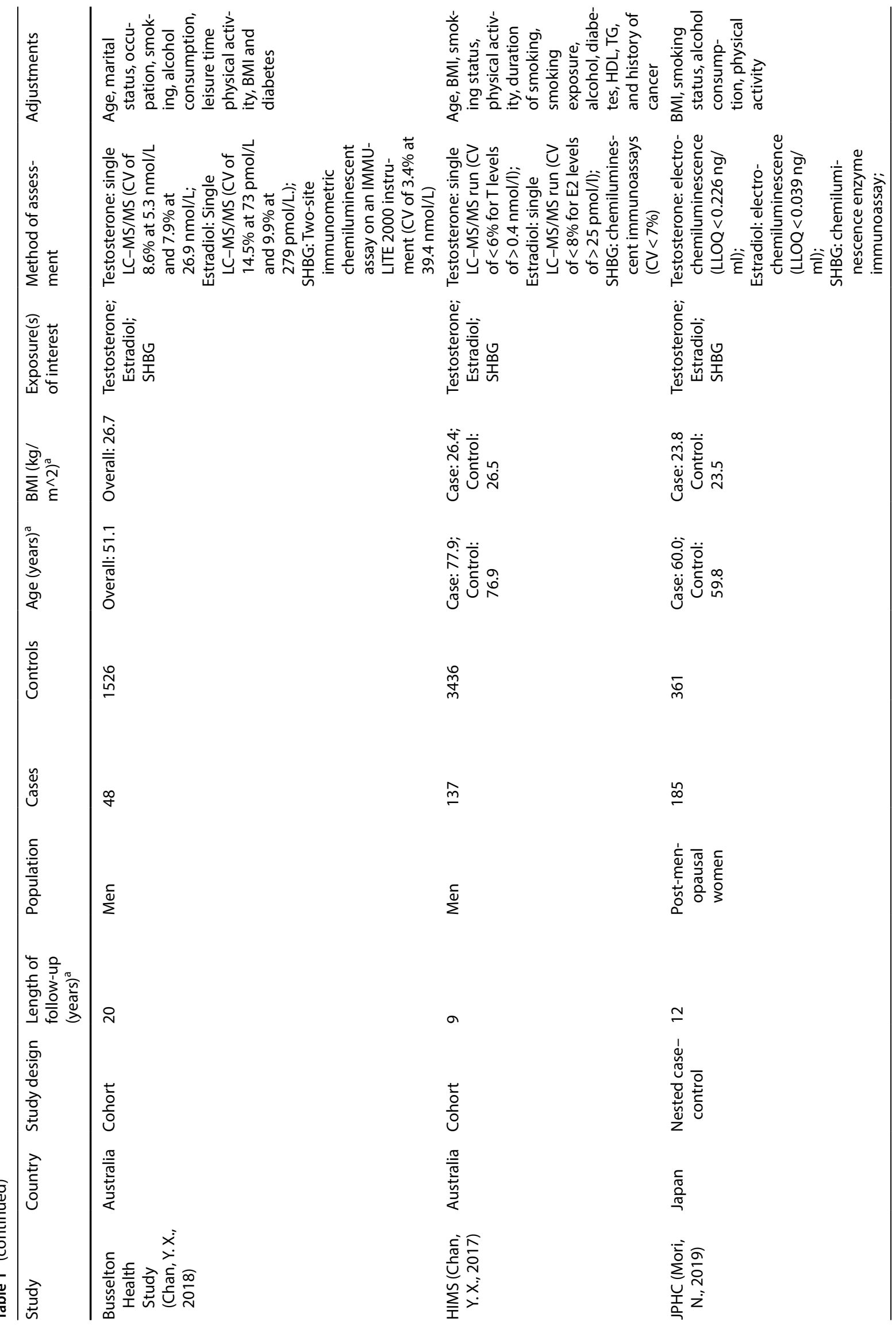




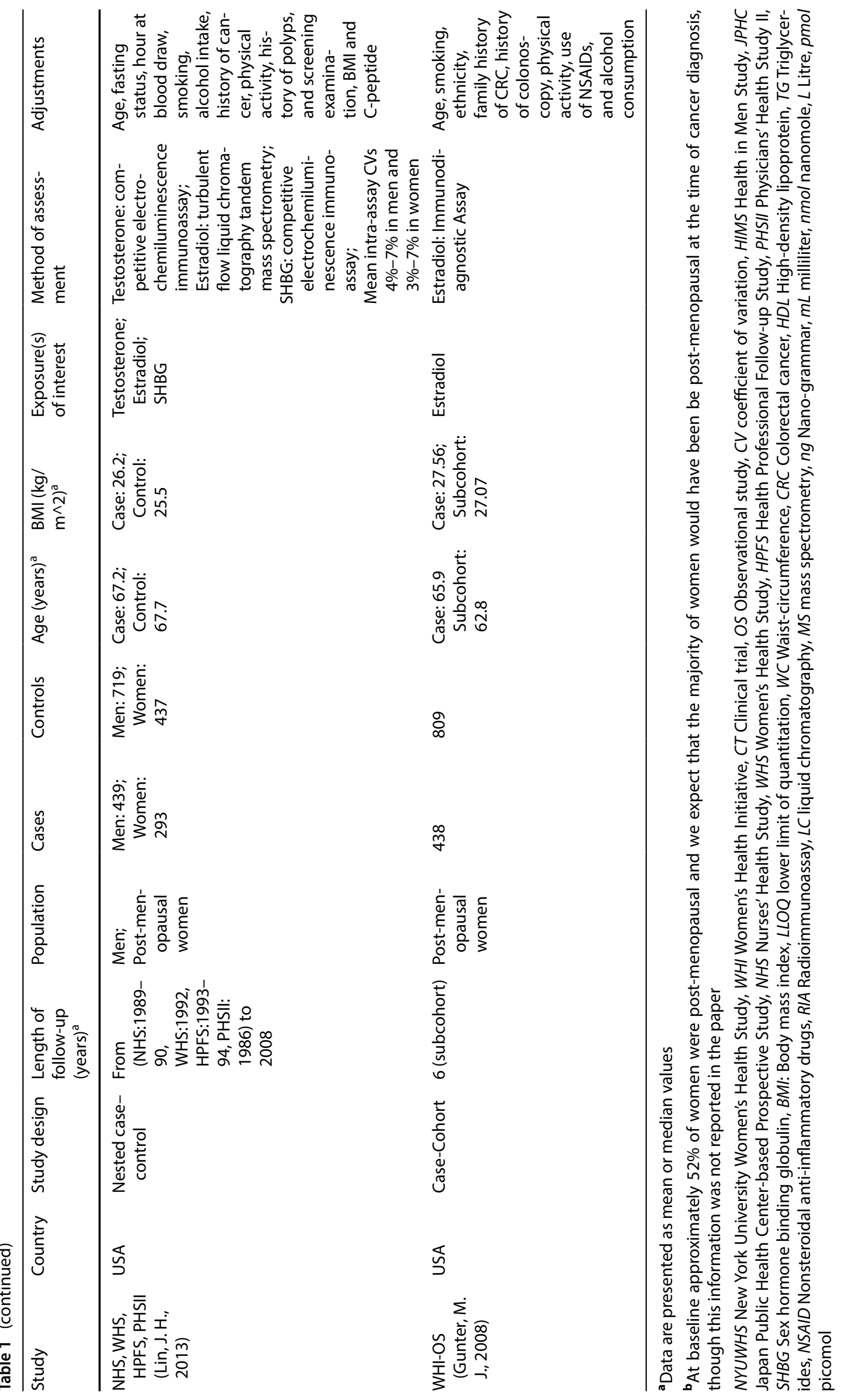


Fig. 1 Flow diagram of studies assessed for eligibility per screening stage
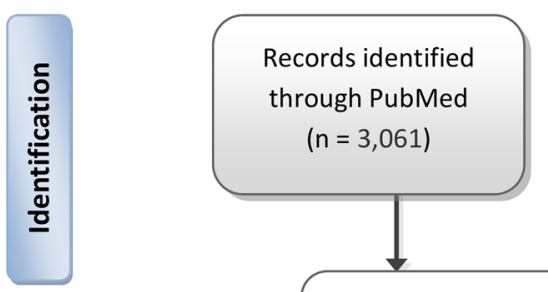

Records identified through Scopus ( $n=2,551)$

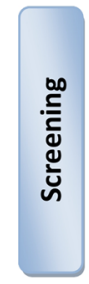

Records after duplicates removed $(n=3,859)$
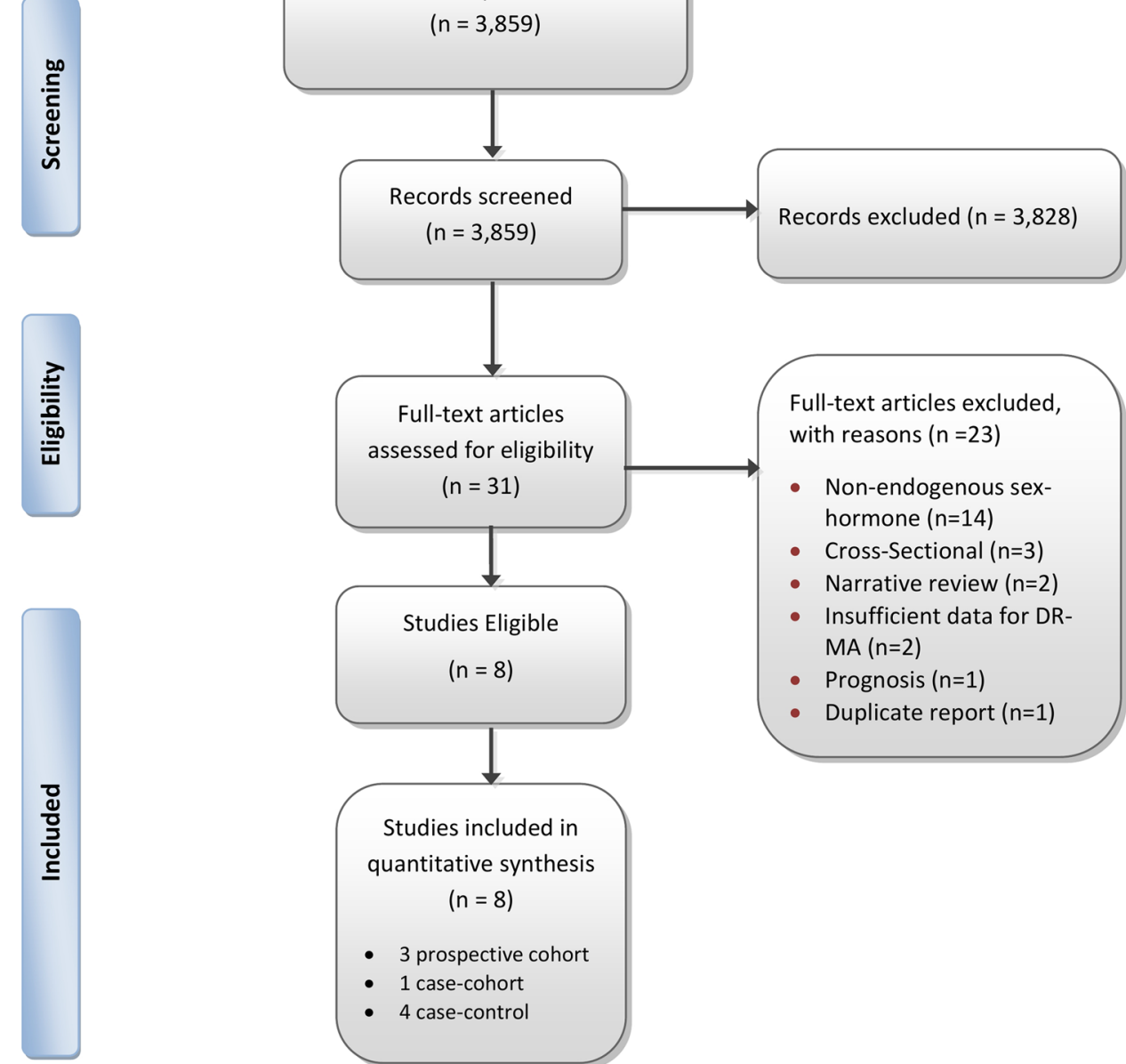

Full-text articles excluded, with reasons $(n=23)$

- Non-endogenous sexhormone $(n=14)$

- Cross-Sectional $(n=3)$

- Narrative review $(n=2)$

- Insufficient data for DR$M A(n=2)$

- Prognosis $(n=1)$

- Duplicate report $(n=1)$

\section{Discussion}

Findings from this systematic review and meta-analysis summarized for the first time the association of pre-diagnostic concentrations of sex steroid hormones in relation to CRC risk. Eight prospective studies were meta-analyzed, but the summary findings did not support an association of estradiol, testosterone and SHBG with risk of CRC in men and postmenopausal women.

The discovery of different estrogen receptors (ER) have revealed a significant role in tissue types other than the female reproductive tract, including the gastrointestinal system [34]. There have been several in vitro studies reporting that estradiol may have tumorigenic effects on colorectal cells [35-37]. The mitogenic activities of estrogens are mediated through their intracellular receptors, ERa and ER [16]. Studies in male mice also suggest that testosterone may play a role in inducing colonic adenomas via its tumour-promoting effects [38]. Another potential indirect 
a Men

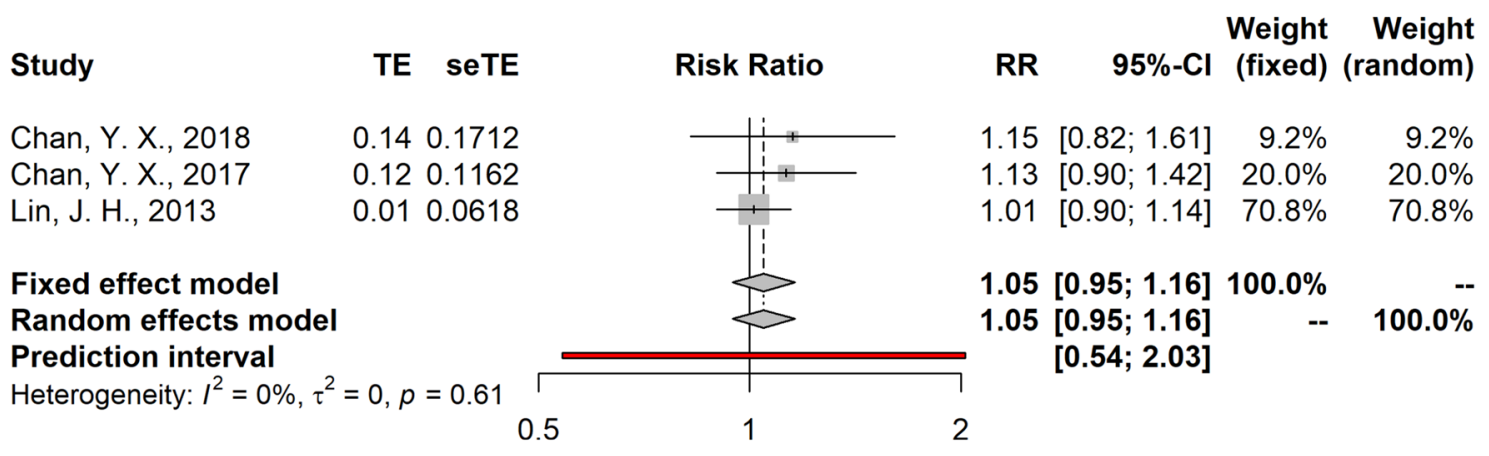

b Women

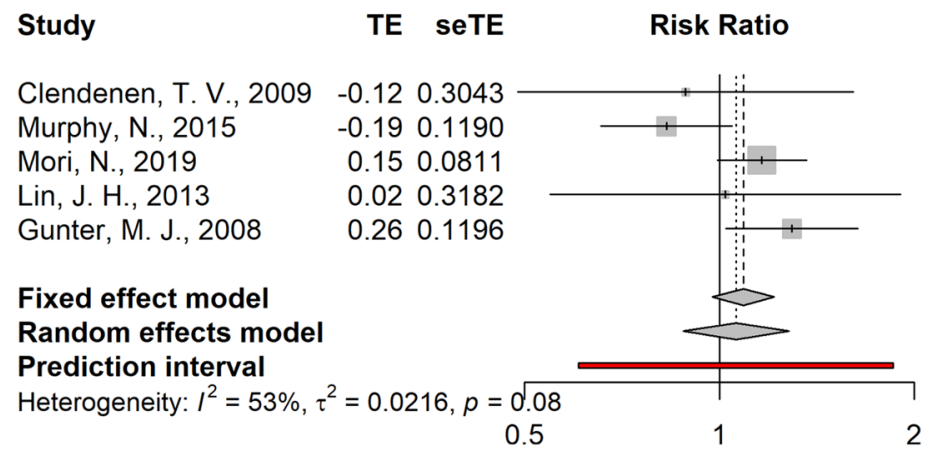

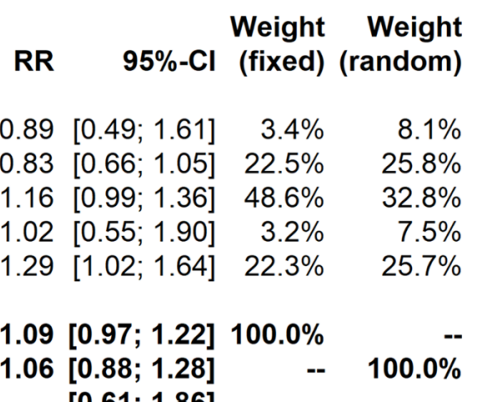

$[0.61 ; 1.86]$

Fig. 2 Summary relative risks and 95\% confidence intervals of prospective studies for the association between estradiol and colorectal cancer risk in men and post-menopausal women. $\mathrm{Cl}$ confidence interval, $R R$ relative risk

mechanism for this effect is the increase in stress hormones, such as cortisol, affecting the tumour environment [39]. The findings from observational studies in humans included in the present meta-analysis, however, are inconsistent. A case-control study nested in four prospective studies (the Nurses' Health Study, the Women's Health Study, the Health Professional Follow-Up Study, and the Physicians' Health Study II), which had 732 CRC cases, did not report any association between estradiol concentrations and CRC risk in men or women [2]. However, the same study found an inverse association of testosterone and SHBG concentrations with CRC in men but not in women [2]. In another case-control study nested in the female WHI-CT, no associations were observed between estradiol concentrations and CRC, whereas higher SHBG concentrations were associated with a higher CRC incidence [25]. In contrast, endogenous estradiol concentrations were positively associated with risk of CRC in the female WHI-OS [18]. Other studies with fewer CRC cases, ranging from 48 to 269, namely the Copenhagen City Heart Study [22], the NYUWHS cohort study [19], the JPHC Study Cohort II [20], and the Busselton Health Study [24] did not report any significant associations between endogenous sex hormone concentrations and CRC risk.

Possible explanations for these discrepancies include differences in the hormone assessment methods, variation in the number of cases and adjustments for confounders. Most included studies adjusted for several factors that may confound the sex hormone and CRC association such as adiposity [40], physical activity [41], smoking, and alcohol intake [42]. However, physical activity, smoking and alcohol were not included as confounders in the NYUWHS [19], and physical 
a Men

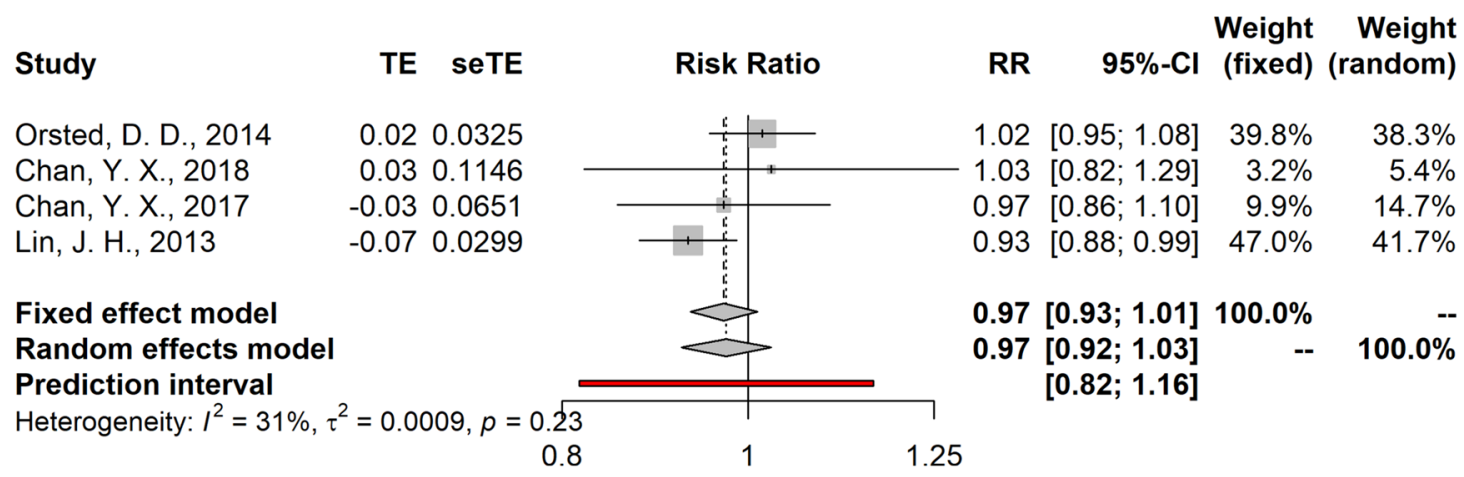

\section{b Women}

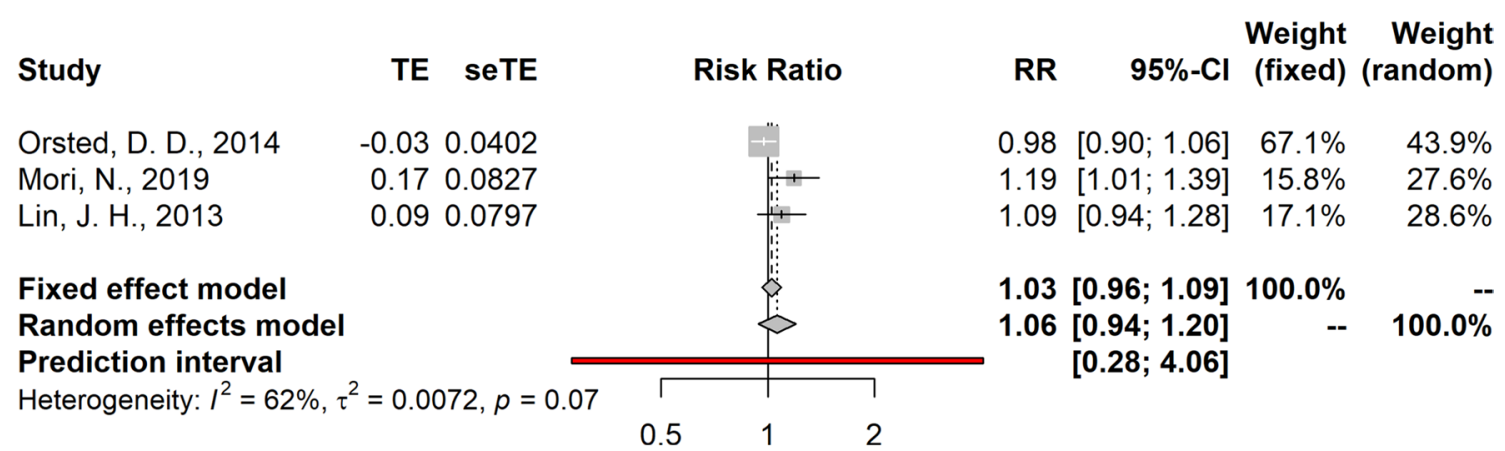

Fig. 3 Summary relative risks and 95\% confidence intervals of prospective studies for the association between testosterone and colorectal cancer risk in men and post-menopausal women. $\mathrm{Cl}$ confidence interval, $R R$ relative risk

activity was not included in the Copenhagen City Heart Study [22]. Variation also existed as a result of the different hormone measurement methods used such as RIA, LC-MS/MS, and electrochemiluminescence [43]. For example, the median SHBG concentrations varied substantially between the studies, namely from 42.4 [25] to $221.2 \mathrm{nmol} / \mathrm{L}$ (converted from $63.8 \mathrm{ng} / \mathrm{ml}$ ) [20] in the female controls. This could partially explain the large heterogeneity observed among the studies examining the relationship between SHBG and CRC in post-menopausal women $\left(I^{2}=76 \%\right)$. In the NYUWHS, there was a large amount of missing data (28.6\%) and a high degree of laboratory error in the estradiol measurements (intrabatch coefficient of variation $=33.5 \%$ ) [19], which might have biased the measurements and the reported associations. Standardization of high-quality sex hormone assays is needed for the validity of epidemiological studies and to draw definitive quantitative conclusions [44].

The strengths of this systematic review and meta-analysis include: (1) the prospective design and long follow-up period of the studies; (2) the inclusion of studies with populations largely free from exogenous administration of sex steroid hormones close to the time of assessment; (3) the inclusion of high-quality studies, as assessed with the "Newcastle-Ottawa Scale".

Several limitations should also be noted. First, due to the observational nature of the studies included, residual confounding cannot be ruled out [45]. Second, the studies we meta-analysed relied on the measurement of sex hormone concentrations only once at baseline, and it is possible that this measurement may not reflect exposure levels across time. However, a previous analysis of postmenopausal women reported that the within-subject correlation coefficients for estradiol, testosterone and SHBG over a 2-3-year period were $0.64,0.88$ and 0.92 respectively [46], 
a Men

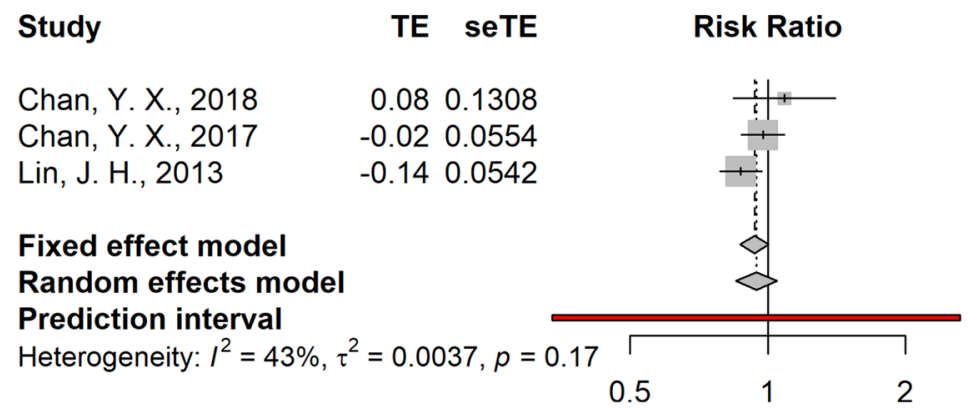

$1.09[0.84 ; 1.41] \quad 8.1 \% \quad 13.8 \%$

$0.98[0.88 ; 1.09] \quad 44.9 \% \quad 42.7 \%$

$0.87[0.79 ; 0.97] \quad 47.0 \% \quad 43.5 \%$

$0.93[0.87 ; 1.01] 100.0 \%$

b Women

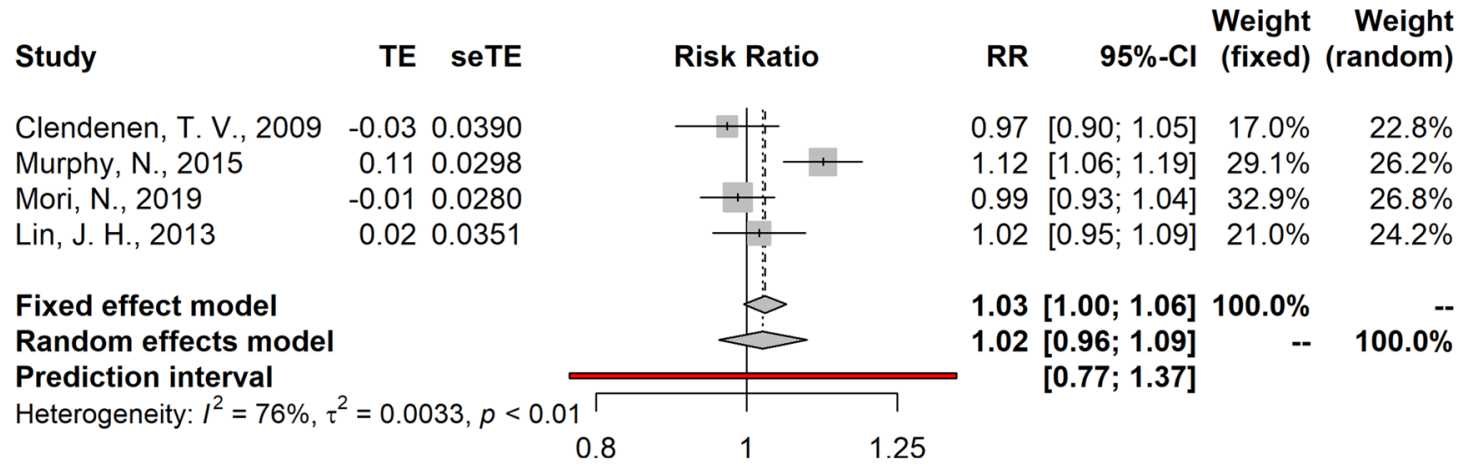

Fig. 4 Summary relative risks and 95\% confidence intervals of prospective studies for the association between sex-hormone binding globulin (SHBG) and colorectal cancer risk in men and post-menopausal women. $C l$ confidence interval, $R R$ relative risk

indicating that single measurements may be reasonably reliable of longer-term exposures. Third, the current available studies were relatively small and they did not provide results by important potential colorectal cancer subtypes (colon vs. rectal) and subgroups (age, adiposity). Only the study by Murphy et al., reported on separate analyses by colon vs. rectal cancer, but statistically significant differences were not observed by disease subtype for estradiol and SHBG concentrations [25]. Furthermore, it was not possible to investigate associations with young onset colorectal cancer, and future studies are warranted to investigate this disease, the incidence of which is increasing lately $[47,48]$.

In conclusion, the results of this systematic review and meta-analysis of prospective studies on the associations between endogenous sex hormone concentrations and CRC risk indicate that circulating concentrations of estradiol, testosterone and SHBG do not appear to be associated with risk of CRC in men and post-menopausal women. The observed lack of consistency in findings among the single studies suggests a need for more research in this area, with a particular focus on large prospective studies and reliable sex hormone assessments.

Authors' contributions KKT and IT designed the study. EB \& CP performed the analysis. All authors interpreted the results. CP and EB drafted the manuscript. All authors critically revised the manuscript for intellectual content. All authors approved the submitted version and are accountable for the integrity of the work.

Funding This research is co-financed by Greece and the European Union (European Social Fund-ESF) through the Operational Programme «Human Resources Development, Education and Lifelong Learning 2014- 2020» in the context of the project "Sex steroid hormones and cancer: a molecular epidemiology study" (MIS 5047651).

Availability of data and materials Not applicable.

Code availability Not applicable.

Declarations 
Competing interests The authors have declared no conflicts of interest.

Open Access This article is licensed under a Creative Commons Attribution 4.0 International License, which permits use, sharing, adaptation, distribution and reproduction in any medium or format, as long as you give appropriate credit to the original author(s) and the source, provide a link to the Creative Commons licence, and indicate if changes were made. The images or other third party material in this article are included in the article's Creative Commons licence, unless indicated otherwise in a credit line to the material. If material is not included in the article's Creative Commons licence and your intended use is not permitted by statutory regulation or exceeds the permitted use, you will need to obtain permission directly from the copyright holder. To view a copy of this licence, visit http://creativecommons.org/licenses/by/4.0/.

\section{References}

1. Ferlay J, Colombet $M$, Soerjomataram I, Mathers C, Parkin DM, Piñeros $M$, et al. Estimating the global cancer incidence and mortality in 2018: GLOBOCAN sources and methods. Int J cancer. 2019 Apr;144(8):1941-53. https://doi.org/10.1002/ijc.31937.

2. Lin JH, Zhang SM, Rexrode KM, Manson JE, Chan AT, Wu K, et al. Association between sex hormones and colorectal cancer risk in men and women. Clin Gastroenterol Hepatol Off Clin Pract J Am Gastroenterol Assoc. 2013 Apr;11(4):419-424.e1. https://doi.org/10.1016/j. cgh.2012.11.012.

3. White A, Ironmonger L, Steele RJC, Ormiston-Smith N, Crawford C, Seims A. A review of sex-related differences in colorectal cancer incidence, screening uptake, routes to diagnosis, cancer stage and survival in the UK. BMC Cancer. 2018 Sep;18(1):906. https://doi.org/10. 1186/s12885-018-4786-7.

4. Beral V, Banks E, Reeves G. Evidence from randomised trials on the long-term effects of hormone replacement therapy. Lancet (London, England). 2002 Sep;360(9337):942-4. https://doi.org/10.1016/S0140-6736(02)11032-4.

5. La Vecchia C, Franceschi S. Reproductive factors and colorectal cancer. Cancer Causes Control. 1991 May;2(3):193-200. https://doi.org/ $10.1007 / B F 00056213$.

6. Grodstein F, Newcomb PA, Stampfer MJ. Postmenopausal hormone therapy and the risk of colorectal cancer: a review and meta-analysis. Am J Med. 1999 May;106(5):574-82. https://doi.org/10.1016/s0002-9343(99)00063-7.

7. Rossouw JE, Anderson GL, Prentice RL, LaCroix AZ, Kooperberg C, Stefanick ML, et al. Risks and benefits of estrogen plus progestin in healthy postmenopausal women: principal results From the Women's Health Initiative randomized controlled trial. JAMA. 2002 Jul;288(3):321-33. https://doi.org/10.1001/jama.288.3.321.

8. Bowel cancer incidence statistics [Internet]. CANCER RESEARCH UK. 2017. http://www.cancerresearchuk.org/health-professional/cancerstatistics/statistics-by-cancer-type/bowel-cancer/incidence\#heading-One

9. Globocan 2020: Colorectal cancer [Internet]. https://gco.iarc.fr/today

10. Luan N-N, Wu L, Gong T-T, Wang Y-L, Lin B, Wu Q-J. Nonlinear reduction in risk for colorectal cancer by oral contraceptive use: a metaanalysis of epidemiological studies. Cancer Causes Control. 2015 Jan;26(1):65-78. https://doi.org/10.1007/s10552-014-0483-2.

11. Lin KJ, Cheung WY, Lai JYC, Giovannucci EL. The effect of estrogen vs combined estrogen-progestogen therapy on the risk of colorectal cancer. Int J Cancer. 2012;130(2):419-30. https://doi.org/10.1002/ijc.26026.

12. Carr PR, Alwers E, Bienert S, Weberpals J, Kloor M, Brenner H, et al. Lifestyle factors and risk of sporadic colorectal cancer by microsatellite instability status: a systematic review and meta-analyses. Ann Oncol Off J Eur Soc Med Oncol. 2018 Apr;29(4):825-34. https:// doi.org/10.1093/annonc/mdy059.

13. Tsilidis KK, Allen NE, Key TJ, Dossus L, Lukanova A, Bakken K, et al. Oral contraceptive use and reproductive factors and risk of ovarian cancer in the European Prospective Investigation into Cancer and Nutrition. Br J Cancer. 2011 Oct;105(9):1436-42. https://doi.org/ 10.1038/bjc.2011.371.

14. Son HJ, Sohn SH, Kim N, Lee H-N, Lee SM, Nam RH, et al. Effect of estradiol in an azoxymethane/dextran sulfate sodium-treated mouse model of colorectal cancer: implication for sex difference in colorectal cancer development. Cancer Res Treat. 2019 Apr;51(2):632-48. https://doi.org/10.4143/crt.2018.060.

15. Roshan MHK, Tambo A, Pace NP. The role of testosterone in colorectal carcinoma: pathomechanisms and open questions. EPMA J. 2016;7(1):22. https://doi.org/10.1186/s13167-016-0071-5.

16. Barzi A, Lenz AM, Labonte MJ, Lenz H-J. Molecular pathways: estrogen pathway in colorectal cancer. Clin cancer Res an Off J Am Assoc Cancer Res. 2013 Nov;19(21):5842-8. https://doi.org/10.1158/1078-0432.CCR-13-0325.

17. Anagnostopoulou V, Pediaditakis I, Alkahtani S, Alarifi SA, Schmidt E-M, Lang F, et al. Differential effects of dehydroepiandrosterone and testosterone in prostate and colon cancer cell apoptosis: the role of nerve growth factor (NGF) receptors. Endocrinology. 2013 Jul;154(7):2446-56. https://doi.org/10.1210/en.2012-2249.

18. Gunter MJ, Hoover DR, Yu H, Wassertheil-Smoller S, Rohan TE, Manson JE, et al. Insulin, insulin-like growth factor-l, endogenous estradiol, and risk of colorectal cancer in postmenopausal women. Cancer Res. 2008 Jan;68(1):329-37. https://doi.org/10.1158/ 0008-5472.CAN-07-2946.

19. Clendenen TV, Koenig KL, Shore RE, Levitz M, Arslan AA, Zeleniuch-Jacquotte A. Postmenopausal levels of endogenous sex hormones and risk of colorectal cancer. Cancer Epidemiol biomarkers Prev a Publ Am Assoc Cancer Res cosponsored by Am Soc Prev Oncol. 2009 Jan;18(1):275-81. https://doi.org/10.1158/1055-9965.EPI-08-0777.

20. Mori N, Sawada N, Iwasaki M, Yamaji T, Goto A, Shimazu T, et al. Circulating sex hormone levels and colorectal cancer risk in Japanese postmenopausal women: the JPHC nested case-control study. Int J cancer. 2019 Sep;145(5):1238-44. https://doi.org/10.1002/ijc.32431.

21. Hyde Z, Flicker L, McCaul KA, Almeida OP, Hankey GJ, Chubb SAP, et al. Associations between testosterone levels and incident prostate, lung, and colorectal cancer A population-based study. Cancer Epidemiol Biomarkers Prev Publ Am Assoc Cancer Res Am Soc Prev Oncol. 2012;21(8):1319-29. https://doi.org/10.1158/1055-9965.EPI-12-0129.

22. Ørsted DD, Nordestgaard BG, Bojesen SE. Plasma testosterone in the general population, cancer prognosis and cancer risk: a prospective cohort study. Ann Oncol Off J Eur Soc Med Oncol. 2014 Mar;25(3):712-8. https://doi.org/10.1093/annonc/mdt590. 
23. Chan YX, Alfonso H, Chubb SAP, Handelsman DJ, Fegan PG, Hankey GJ, et al. Higher dihydrotestosterone is associated with the incidence of lung cancer in older men. Horm Cancer. 2017 Apr;8(2):119-26. https://doi.org/10.1007/s12672-017-0287-4.

24. Chan YX, Knuiman MW, Divitini ML, Handelsman DJ, Beilby JP, Yeap BB. Lower circulating androgens are associated with overall cancer risk and prostate cancer risk in men aged 25-84 years from the Busselton health study. Horm Cancer. 2018 Dec;9(6):391-8. https://doi. org/10.1007/s12672-018-0346-5.

25. Murphy N, Strickler HD, Stanczyk FZ, Xue X, Wassertheil-Smoller S, Rohan TE, et al. A Prospective evaluation of endogenous sex hormone levels and colorectal cancer risk in postmenopausal women. J Natl Cancer Inst. 2015. https://doi.org/10.1093/jnci/djv210.

26. Ouzzani M, Hammady H, Fedorowicz Z, Elmagarmid A. Rayyan-a web and mobile app for systematic reviews. Syst Rev. 2016 Dec;5(1):210. https://doi.org/10.1186/s13643-016-0384-4.

27. Wells GA, Shea B, O'Connell D, Peterson J, Welch V, Losos M TP. The Newcastle-Ottawa Scale (NOS) for assessing the quality of nonrandomised studies in meta-analyses. [Internet]. http://www.ohri.ca/programs/clinical_epidemiology/oxford.asp

28. Greenland S, Longnecker MP. Methods for trend estimation from summarized dose-response data, with applications to meta-analysis. Am J Epidemiol. 1992. https://doi.org/10.1093/oxfordjournals.aje.a116237.

29. DerSimonian R, Laird N. Meta-analysis in clinical trials. Control Clin Trials. 1986 Sep;7(3):177-88. https://doi.org/10.1016/0197-2456(86) 90046-2.

30. DerSimonian R, Laird N. Meta-analysis in clinical trials revisited. Contemp Clin Trials. 2015 Nov;45(Pt A):139-45. https://doi.org/10.1016/j. cct.2015.09.002.

31. Higgins JPT, Thompson SG, Deeks JJ, Altman DG. Measuring inconsistency in meta-analyses. BMJ. 2003. https://doi.org/10.1136/bmj.327. 7414.557.

32. Higgins JPT, Thompson SG, Spiegelhalter DJ. A re-evaluation of random-effects meta-analysis. J R Stat Soc Ser A Stat Soc. 2009. https:// doi.org/10.1111/j.1467-985X.2008.00552.x.

33. R Core Team; R: A language and environment for statistical computing. [Internet]. Vienna, Austria.: R Foundation for Statistical Computing; 2018. https://www.r-project.org/

34. Gustafsson JA. Estrogen receptor beta-a new dimension in estrogen mechanism of action. J Endocrinol. 1999 Dec;163(3):379-83. https:// doi.org/10.1677/joe.0.1630379.

35. Narayan S, Rajakumar G, Prouix H, Singh P. Estradiol is trophic for colon cancer in mice: effect on ornithine decarboxylase and c-myc messenger RNA. Gastroenterology. 1992 Dec;103(6):1823-32. https://doi.org/10.1016/0016-5085(92)91441-6.

36. Di Domenico M, Castoria G, Bilancio A, Migliaccio A, Auricchio F. Estradiol activation of human colon carcinoma-derived Caco-2 cell growth. Cancer Res. 1996 Oct;56(19):4516-21.

37. Hennessy BA, Harvey BJ, Healy V. 17beta-Estradiol rapidly stimulates c-fos expression via the MAPK pathway in T84 cells. Mol Cell Endocrinol. 2005 Jan;229(1-2):39-47. https://doi.org/10.1016/j.mce.2004.10.001.

38. Amos-Landgraf JM, Heijmans J, Wielenga MCB, Dunkin E, Krentz KJ, Clipson L, et al. Sex disparity in colonic adenomagenesis involves promotion by male hormones, not protection by female hormones. Proc Natl Acad Sci USA. 2014 Nov;111(46):16514-9. https://doi.org/ $10.1073 /$ pnas.1323064111.

39. Carroll RE, Goodlad RA, Poole AJ, Tyner AL, Robey RB, Swanson SM, et al. Reduced susceptibility to azoxymethane-induced aberrant crypt foci formation and colon cancer in growth hormone deficient rats. Growth Horm IGF Res Off J Growth Horm Res Soc Int IGF Res Soc. 2009 Oct;19(5):447-56. https://doi.org/10.1016/j.ghir.2009.02.001.

40. Bardou M, Barkun AN, Martel M. Obesity and colorectal cancer. Gut. 2013 Jun;62(6):933-47. https://doi.org/10.1136/gutjnl-2013-304701.

41. Diet, Nutrition, Physical Activity, and Cancer: a Global Perspective. Continuous Update Project Expert Report [Internet]. 2018. https:// www.wcrforg/dietandcancer

42. Fedirko V, Tramacere I, Bagnardi V, Rota M, Scotti L, Islami F, et al. Alcohol drinking and colorectal cancer risk: an overall and dose-response meta-analysis of published studies. Ann Oncol Off J Eur Soc Med Oncol. 2011 Sep;22(9):1958-72. https://doi.org/10.1093/annonc/mdq653.

43. Nelson RE, Grebe SK, Okane DJ, Singh RJ. Liquid chromatography-tandem mass spectrometry assay for simultaneous measurement of estradiol and estrone in human plasma. Clin Chem. 2004;50(2):373-84. https://doi.org/10.1373/clinchem.2003.025478.

44. Stanczyk FZ, Lee JS, Santen RJ. Standardization of steroid hormone assays: why, how, and when? Cancer Epidemiol Biomarkers Prev Publ Am Assoc Cancer Res Am Soc Prev Oncol. 2007 Sep;16(9):1713-9. https://doi.org/10.1158/1055-9965.EPI-06-0765.

45. Lipsitch M, Tchetgen Tchetgen E, Cohen T. Negative controls: a tool for detecting confounding and bias in observational studies. Epidemiology. 2010 May;21(3):383-8. https://doi.org/10.1097/EDE.0b013e3181d61eeb.

46. Hankinson SE, Manson JE, Spiegelman D, Willett WC, Longcope C, Speizer FE. Reproducibility of plasma hormone levels in postmenopausal women over a 2-3-year period. Cancer Epidemiol Biomarkers Prev Publ Am Assoc Cancer Res Am Soc Prev Oncol. 1995 Sep;4(6):649-54.

47. Bailey CE, Hu C-Y, You YN, Bednarski BK, Rodriguez-Bigas MA, Skibber JM, et al. Increasing disparities in the age-related incidences of colon and rectal cancers in the United States, 1975-2010. JAMA Surg. 2015 Jan;150(1):17-22. https://doi.org/10.1001/jamasurg.2014.1756.

48. Sung JJY, Chiu H-M, Jung K-W, Jun JK, Sekiguchi M, Matsuda T, et al. Increasing trend in young-onset colorectal cancer in Asia: more cancers in men and more rectal cancers. Am J Gastroenterol. 2019 Feb;114(2):322-9. https://doi.org/10.14309/ajg.0000000000000133.

Publisher's Note Springer Nature remains neutral with regard to jurisdictional claims in published maps and institutional affiliations. 